\title{
The Use of Serum Procalcitonin as a Diagnostic and Prognostic Biomarker in Chronic Obstructive Pulmonary Disease Exacerbations: A Literature Review Update
}

\author{
Nikolaos-Dimitrios Pantzaris ${ }^{\mathrm{a}, \mathrm{c}}$, Diamantina-Xanthi Spiliotia ${ }^{\mathrm{a}}$ Aikaterini Psaromyalou ${ }^{\mathrm{a}}$, \\ Ioanna Koniari ${ }^{\mathrm{b}}$, Dimitrios Velissaris ${ }^{\mathrm{a}}$
}

\begin{abstract}
Acute exacerbations of chronic obstructive pulmonary disease (AECOPD) are a major complication in COPD patients which can be triggered by bacterial or viral infections, environmental pollutants and other causes. Procalcitonin (PCT), a peptide that markedly increases in cases of bacterial infection, has been extensively investigated as a biomarker in the diagnosis, prognosis and treatment in patients with AECOPD. A number of studies published in the last decade, tried to investigate whether PCT levels can differentiate between bacterial and other causes of exacerbations, if they can be used as a guide for optimal antibiotic therapy and if they can be a tool in the assessment of the severity and the need for further interventions in the management of those patients. This review aims to gather, summarize and critically present all the available data to date.
\end{abstract}

Keywords: Procalcitonin; PCT; COPD; Chronic obstructive pulmonary disease; AECOPD; COPD exacerbation

\section{Introduction}

Chronic obstructive pulmonary disease (COPD) remains a common health and social problem with high morbidity and mortality rates [1]. Exacerbations of the disease pose a critical threat to public health and are related to a variable underlying pathophysiology. The identification of biological markers able to assess this clinical entity, is an area of ongoing interest. Serum procalcitonin (PCT) measurement has been used as a tool for the evaluation and treatment of patients with acute exacerbation of COPD (AECOPD) yielding various results, probably due to the heterogeneity of the

Manuscript submitted April 30, 2018, accepted May 21, 2018

anternal Medicine Department, University Hospital of Patras, Rion, Greece bepartment of Interventional Electrophysiology, Royal Brompton Hospital, London, UK

${ }^{\mathrm{c} C}$ Corresponding Author: Nikolaos-Dimitrios Pantzaris, Internal Medicine Department, University Hospital of Patras, Rion, Greece.

Email: npantzaris@gmail.com affected population, as well as its complicated pathogenicity.

The aim of this review is to summarize the current bibliography regarding the potential uses of PCT as a diagnostic and prognostic biomarker in patients suffering from AECOPD. A PubMed/Medline search was conducted from inception to March 2018, applying no language restrictions. The search terms used were: ("calcitonin" [MeSH Terms] OR "calcitonin" [All Fields] OR "procalcitonin" [All Fields]) AND ("pulmonary disease, chronic obstructive" [MeSH Terms] OR ("pulmonary" [All Fields] AND "disease" [All Fields] AND "chronic" [All Fields] AND "obstructive" [All Fields]). A total of 142 articles were originally retrieved. All original studies examining PCT serum levels in adult patients with AECOPD were included. Bibliographies from the extracted articles were also reviewed to identify any additional relevant publications. This resulted in a total of 31 original clinical studies and three systematic meta-analyses.

\section{Acute Exacerbations of COPD}

AECOPD is a sudden worsening of COPD symptoms (shortness of breath, changes in the quantity and color of expectorated sputum) and may be triggered by a bacterial or viral infection, environmental pollutants, cold weather or interruption of regular treatment. The underlying pathophysiology consists of an increased airway inflammation which results in hyperinflation, and reduction in expiratory air flow and gas exchange $[2,3]$.

AECOPD is the leading cause of hospital admissions and death in patients suffering from this clinical entity. Each exacerbation worsens the patient's respiratory function, performance status, coexisting conditions and increases the risk of subsequent exacerbations [4]. A novel approach to estimate the severity of AECOPD and predict its outcome is the use of serum biomarkers. Exacerbations of the disease are characterized by the presence of elevated inflammatory biomarkers, such as total white blood cell count (WBC), C-reactive protein (CRP), plasma fibrinogen, IL-6 and PCT, which increase acutely during the course of the deterioration of the disease $[5,6]$.

\section{PCT as a Serum Biomarker}

PCT, a precursor of calcitonin, is a 116-amino acid peptide 
member of the calcitonin superfamily. PCT is released from the thyroidal $\mathrm{C}$ cells and is the precursor of calcitonin. Its normal serum concentrations are less than $0.05 \mathrm{ng} / \mathrm{mL}$. PCT is an acute-phase protein with faster kinetics than CRP and erythrocyte sedimentation rate (ESR) [7]. The biological activity of procalcitonin is considered to be part of the complex inflammatory cascade of the immune system.

PCT has been shown to be elevated in bacterial infections, but remains low in viral infections and other inflammatory conditions $[8,9]$. Based on that, it has been proposed that PCT could be useful in the evaluation of patients with COPD during the phase of acute exacerbation of bacterial origin. However, the chronically elevated inflammatory status of the underlying disease and the commonly developed colonization of the airways in these patients pose some limitations in the interpretation of PCT levels during the acute exacerbation.

\section{PCT in the Diagnosis of the AECOPD Etiology}

A summary of the original studies reviewed, including their relevant findings regarding PCT in the diagnosis and treatment of AECOPD, is presented in Table 1.

One of the main questions asked in the majority of the studies is whether PCT levels can be used to distinguish AECOPD of bacterial origin from that of other causes. This distinction would prove very useful in everyday clinical practice, as it would reveal the patients that will require and benefit from antibiotic use during the AECOPD. Several studies found that PCT levels can be used in the differential diagnosis of bacterial AECOPD from non-bacterial causes proposing some possible cut-off values [10, 13, 24, 29].

In a small case-control study in 2009 by using a cut-off point of $0.155 \mu \mathrm{g} / \mathrm{L}$ for $\mathrm{PCT}$, the sensitivity and specificity for the diagnosis of bacterial infection in patients with an AECOPD were $93.3 \%$ and $60 \%$ respectively [41]. In ICU patients with AECOPD, Nseir et al concluded to a cut-off value of 0.5 $\mu \mathrm{g} / \mathrm{L}$ suggesting bacterial isolation [13] and Ergan et al found that the optimal admission PCT threshold was $0.25 \mu \mathrm{g} / \mathrm{L}$ in order to identify patients with a bacterial exacerbation [29]. Daubin et al concluded to the stricter cut-off value of $0.1 \mu \mathrm{g} / \mathrm{L}$ by founding a positive bacterial culture in a significant number of patients with $\mathrm{PCT}_{\max }$ values $>0.1$ and $<0.25 \mu \mathrm{g} / \mathrm{L}$ [42].

Nevertheless, there are also a number studies concluding that PCT values do not significantly differ between bacterial and non-bacterial AECOPD. Two case-control studies comparing PCT levels between AECOPD patients with purulent and non-purulent sputum by Soler et al and Gao et al found that the differences were statistically insignificant [21, 37]. Chang et al in 2015 also found that they were no significant differences in PCT levels between bacterial positive and bacterial negative AECOPD patients, neither between virus-positive and virus-negative AECOPD patients [28].

In a large prospective cohort study enrolling 224 patients in 2012, Falsey et al found that high PCT levels were correlated with more severe illness and point to the possibility of pneumonia in hospitalized individuals with AECOPD, but low values do not rule out bacterial infection [20]. Two fur- ther studies by Lacoma et al and Colak et al concluded that AECOPD patients with pneumonia have significant higher PCT values than those without pneumonic involvement [19, 38]. Higher PCT levels have also been linked to exacerbation severity and the need for non-invasive positive pressure ventilation (NPPV) $[15,22,33]$ as well as to an increased length of hospitalization [36].

Flattet et al in a large recent retrospective cohort study enrolling 359 patients found that although higher PCT levels were significantly associated with a worse prognosis (hazard ratio (HR): $1.009(1.001-1.017))$, respiratory rate at admission seems to be the most prognostic clinical parameter and baseline pulmonary function of the patient remains the strongest predictor of mortality and readmission [35].

\section{PCT-Guided Antibiotic Therapy in AECOPD}

Although the role of PCT in the distinction between bacterial, viral and other causes of AECOPD is still a subject of debate, with conflicting results and relatively small studies conducted so far, data regarding its role in the guidance of antibiotic therapy in those patients are more conclusive. In one of the earlier studies in 2007, Stolz et al in a randomized control trial with 208 AECOPD inpatients showed that PCT guidance reduced antibiotic prescription ( $40 \%$ versus $72 \%$, respectively; $\mathrm{P}<$ 0.0001 ) and antibiotic exposure (relative risk (RR): 0.56; $95 \%$ confidence interval (CI): $0.43-0.73 ; \mathrm{P}<0.0001$ ) compared to standard therapy. Both groups had a similar rehospitalization rate, and mean time to the next exacerbation in the preceding 6 months [12].

Two more randomized controlled trials published in 2016 also concluded that PCT-guided protocols have similar overall treatment success rates compared to standard treatment [30] and they reduce the duration of antibiotic exposure without showing significant difference in rehospitalization, death or ICU admission, all within 28 days [31]. Although in 2010, Daniels et al, in a retrospective cohort study including 243 AECOPD of 205 patients, concluded that doxycycline had a significant effect in patients with a PCT level $<0.1 \mu \mathrm{g} / \mathrm{L}$, suggesting that patients with low PCT values do benefit from antibiotics [16], Wang et al, in his randomized control trial, showed that antibiotic treatment is no better than placebo in AECOPD with a PCT level $<0.1 \mu \mathrm{g} / \mathrm{L}[30]$.

A metanalysis conducted in early 2018 by Lin et al with data from 4 randomized control trials involving 679 patients with AECOPD found that PCT-guided treatment significantly reduced antibiotic use (OR: 0.26, 95\% CI: $0.14-0.50, \mathrm{P}<$ 0.0001 ) when compared to standard treatment, without increasing clinical failure (OR: 1.10, 95\% CI: $0.70-1.74, \mathrm{P}=$ $0.68 ; \mathrm{I}_{2}=0 \%$ ) or mortality (OR: $0.86,95 \% \mathrm{CI}: 0.44-1.68, \mathrm{P}$ $=0.66)$. The rates of exacerbation at the follow-up period and readmission were similar in both groups [43]. Mathioudakis et al in a metanalysis of eight clinical trials evaluating 1,062 patients with AECOPD, published in early 2017, concluded that PCT-guidance decreased antibiotic prescription (RR: 0.56, 95\% CI: $0.43-0.73$ ) and total antibiotic exposure (mean difference: $-3.83,95 \%$ CI: -4.32 - -3.35), with no impact on clini- 

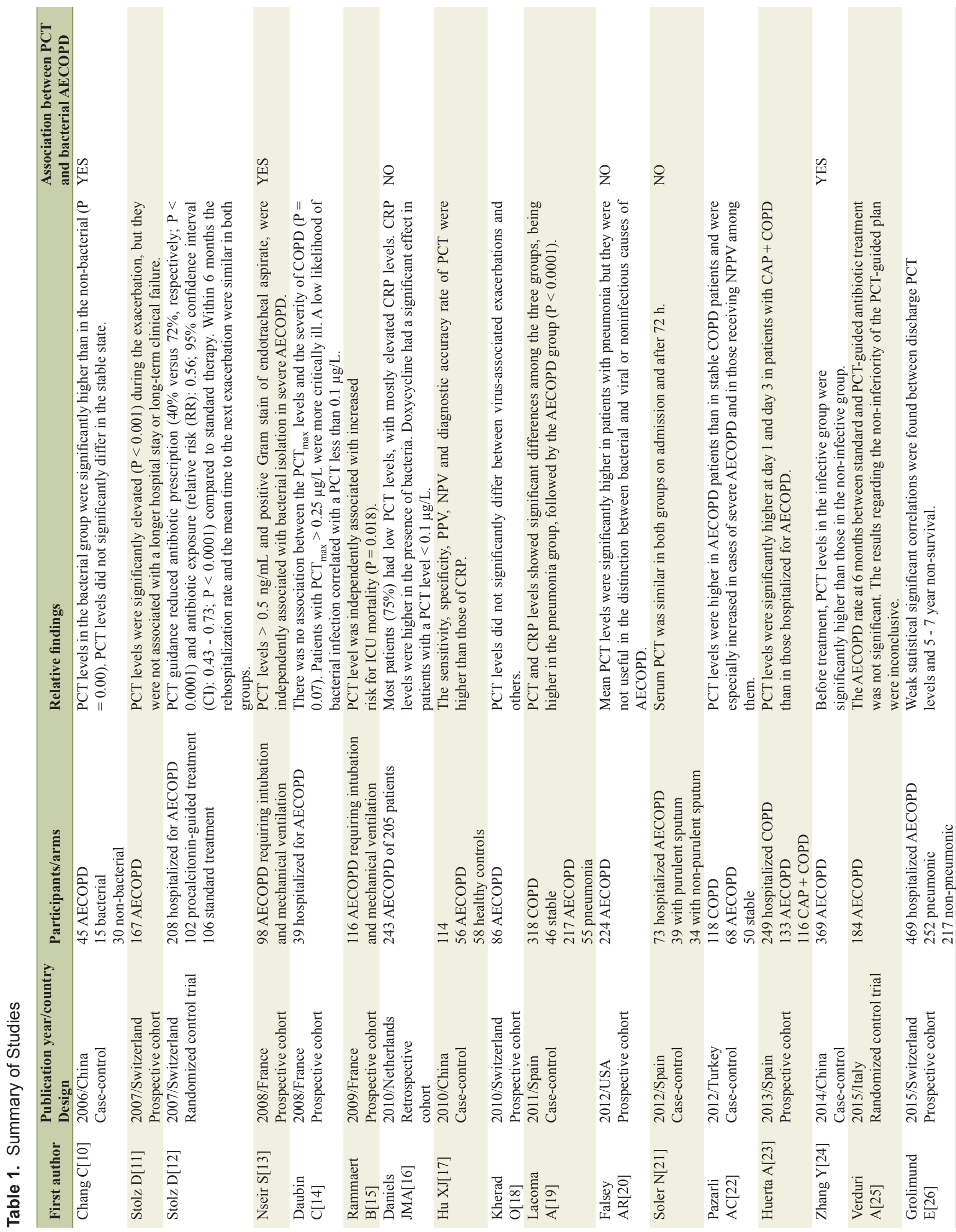

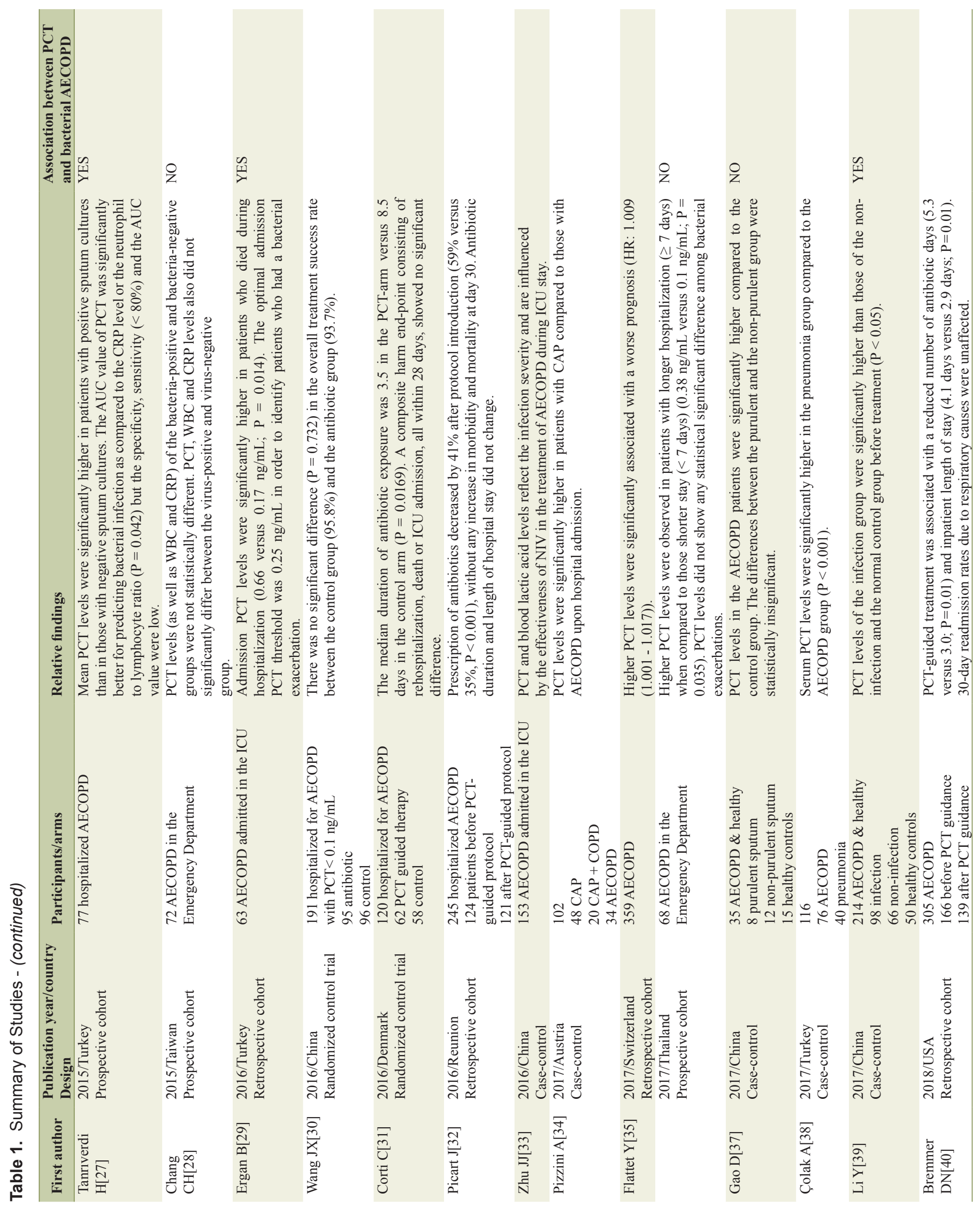
cal outcomes such as rate of treatment failure (RR: $0.81,95 \%$ CI: 0.62 - 1.06), length of hospitalization (MD: $-0.76,95 \%$ CI: - 1.95 - 0.43), exacerbation recurrence rate (RR: 0.96, 95\% CI: $0.69-1.35$ ) or mortality (RR: $0.99,95 \%$ CI: $0.58-1.69$ ). Nonetheless, due to the methodological limitations and the small overall study population, the quality of the available evidence was considered low to moderate, and the authors highlighted the need for further, well-designed randomized control trials [44].

A theoretical model comparing the health and economic consequences of a PCT-guided prescription practice and clinical decision-making strategy compared to current practice in hospitalized patients with AECOPD in three countries, showed that a PCT-guided strategy is also likely to be more cost-effective compared to current practice. The percentages of patients who start with antibiotic treatment, as well as the duration of antibiotic therapy, are reduced with the PCT algorithm, and this leads to a decrease in total costs per patient [45].

Although the body of evidence suggesting the use of PCT in the decision process when treating patients with AECOPD is growing, with several randomized control trials and metanalyses supporting its use, the implementation of the guidance in everyday clinical practice has been poor. In a series of cross-sectional and longitudinal multivariable analyses with data from 2009 - 2011 and 2013 - 2014 from a sample of 505 hospitals in the USA, no significant difference was found in antibiotic treatment rates or duration of therapy between hospitals that had adopted PCT guidance compared with those that had not [46]. This could be attributed to a reluctance of clinicians to change their practice, but it could also be quite more complicated. The prevalence of COPD is very high and the variability of patients and their comorbidities are very extensive. Further research to strengthen current evidence is warranted.

\section{Conclusions}

In the last decade, several studies have tried to establish the potential roles PCT could play in the diagnosis and management of patients with AECOPD. Most of the currently available studies are relatively small and have several limitations and weaknesses. Nevertheless, its use towards the rationalization of antibiotic prescription in those patients seems very promising. An optimized antibiotic treatment will benefit both the COPD patient and the healthcare system. Studies determining prognosis stratification and planned interventions in specific patient groups will be very useful. Further investigation of PCT levels and the optimal cut-off values in order to differentiate between the underlying causes of the acute exacerbations is also warranted.

\section{Conflict of Interest}

This work was supported solely by Department funds. All authors state that they do not have any conflicts of interest to report.

\section{Author Contributions}

NP did literature search and wrote the paper. DS wrote and edited the paper. AP did literature search. IK did literature search. DV wrote and supervised the paper.

\section{Disclosure}

All authors have read, approved the manuscript and meet the ICMJE authorship criteria.

\section{References}

1. Ko M, Lee Y, Chen C, Chou P, Chu D. Prevalence of and predictors for frequent utilization of emergency department: a population-based study. Medicine (Baltimore). 2015;94(29):e1205.

2. Rabe KF, Hurd S, Anzueto A, Barnes PJ, Buist SA, Calverley P, Fukuchi Y, et al. Global strategy for the diagnosis, management, and prevention of chronic obstructive pulmonary disease: GOLD executive summary. Am J Respir Crit Care Med. 2007;176(6):532-555.

3. van Geffen WH, Slebos DJ, Kerstjens HA. Hyperinflation in COPD exacerbations. Lancet Respir Med. 2015;3(12):e43-44.

4. Vogelmeier C, Hederer B, Glaab T, Schmidt H, Ruttenvan Molken MP, Beeh KM, Rabe KF, et al. Tiotropium versus salmeterol for the prevention of exacerbations of COPD. N Engl J Med. 2011;364(12):1093-1103.

5. Wedzicha JA, Seemungal TA, MacCallum PK, Paul EA, Donaldson GC, Bhowmik A, Jeffries DJ, et al. Acute exacerbations of chronic obstructive pulmonary disease are accompanied by elevations of plasma fibrinogen and serum IL-6 levels. Thromb Haemost. 2000;84(2):210-215.

6. Dentener MA, Creutzberg EC, Schols AM, Mantovani A, van't Veer C, Buurman WA, Wouters EF. Systemic antiinflammatory mediators in COPD: increase in soluble interleukin 1 receptor II during treatment of exacerbations. Thorax. 2001;56(9):721-726.

7. Schneider HG, Lam QT. Procalcitonin for the clinical laboratory: a review. Pathology. 2007;39(4):383-390.

8. Wacker C, Prkno A, Brunkhorst FM, Schlattmann P. Procalcitonin as a diagnostic marker for sepsis: a systematic review and meta-analysis. Lancet Infect Dis. 2013;13(5):426-435.

9. Karzai W, Oberhoffer M, Meier-Hellmann A, Reinhart K. Procalcitonin - a new indicator of the systemic response to severe infections. Infection. 1997;25(6):329-334.

10. Chang C, Yao WZ, Chen YH, Liu ZY, Zhang XW. [The changes and clinical implications of serum procalcitonin in acute exacerbations of chronic obstructive pulmonary disease]. Zhonghua Jie $\mathrm{He} \mathrm{He} \mathrm{Hu} \mathrm{Xi} \mathrm{Za} \mathrm{Zhi.}$ 2006;29(7):444-447.

11. Stolz D, Christ-Crain M, Morgenthaler NG, Leuppi $\mathrm{J}$, Miedinger D, Bingisser R, Muller C, et al. Copeptin, C-reactive protein, and procalcitonin as prognos- 
tic biomarkers in acute exacerbation of COPD. Chest. 2007;131(4):1058-1067.

12. Stolz D, Christ-Crain M, Bingisser R, Leuppi J, Miedinger D, Muller C, Huber P, et al. Antibiotic treatment of exacerbations of COPD: a randomized, controlled trial comparing procalcitonin-guidance with standard therapy. Chest. 2007;131(1):9-19.

13. Nseir S, Cavestri B, Di Pompeo C, Diarra M, Brisson H, Lemyze M, Roussel-Delvallez M, et al. Factors predicting bacterial involvement in severe acute exacerbations of chronic obstructive pulmonary disease. Respiration. 2008;76(3):253-260.

14. Daubin C, Parienti JJ, Vabret A, Ramakers M, Fradin S, Terzi N, Freymuth F, et al. Procalcitonin levels in acute exacerbation of COPD admitted in ICU: a prospective cohort study. BMC Infect Dis. 2008;8:145.

15. Rammaert B, Verdier N, Cavestri B, Nseir S. Procalcitonin as a prognostic factor in severe acute exacerbation of chronic obstructive pulmonary disease. Respirology. 2009;14(7):969-974.

16. Daniels JM, Schoorl M, Snijders D, Knol DL, Lutter R, Jansen HM, Boersma WG. Procalcitonin vs C-reactive protein as predictive markers of response to antibiotic therapy in acute exacerbations of COPD. Chest. 2010;138(5):1108-1115.

17. Hu XJ, Zhou F, Qiu YR, Li Q. [Diagnostic value of serum procalcitonin and $\mathrm{C}$-reaction protein in acute exacerbation of chronic bronchitis]. Nan Fang Yi Ke Da Xue Xue Bao. 2010;30(7):1618-1620.

18. Kherad O, Kaiser L, Bridevaux PO, Sarasin F, Thomas Y, Janssens JP, Rutschmann OT. Upper-respiratory viral infection, biomarkers, and COPD exacerbations. Chest. 2010;138(4):896-904.

19. Lacoma A, Prat C, Andreo F, Lores L, Ruiz-Manzano J, Ausina V, Dominguez J. Value of procalcitonin, C-reactive protein, and neopterin in exacerbations of chronic obstructive pulmonary disease. Int J Chron Obstruct Pulmon Dis. 2011;6:157-169.

20. Falsey AR, Becker KL, Swinburne AJ, Nylen ES, Snider RH, Formica MA, Hennessey PA, et al. Utility of serum procalcitonin values in patients with acute exacerbations of chronic obstructive pulmonary disease: a cautionary note. Int J Chron Obstruct Pulmon Dis. 2012;7:127-135.

21. Soler N, Esperatti M, Ewig S, Huerta A, Agusti C, Torres A. Sputum purulence-guided antibiotic use in hospitalised patients with exacerbations of COPD. Eur Respir J. 2012;40(6):1344-1353.

22. Pazarli AC, Koseoglu HI, Doruk S, Sahin S, Etikan I, Celikel S, Berktas B. Procalcitonin: Is it a predictor of noninvasive positive pressure ventilation necessity in acute chronic obstructive pulmonary disease exacerbation? J Res Med Sci. 2012;17(11):1047-1051.

23. Huerta A, Crisafulli E, Menendez R, Martinez R, Soler N, Guerrero M, Montull B, et al. Pneumonic and nonpneumonic exacerbations of COPD: inflammatory response and clinical characteristics. Chest. 2013;144(4):11341142 .

24. Zhang Y, Zhou L. [Diagnostic value of C-reactive protein and procalcitonin for bacterial infection in acute exacer- bations of chronic obstructive pulmonary disease]. Zhong Nan Da Xue Xue Bao Yi Xue Ban. 2014;39(9):939-943.

25. Verduri A, Luppi F, D'Amico R, Balduzzi S, Vicini R, Liverani A, Ruggieri V, et al. Antibiotic treatment of severe exacerbations of chronic obstructive pulmonary disease with procalcitonin: a randomized noninferiority trial. PLoS One. 2015;10(3):e0118241.

26. Grolimund E, Kutz A, Marlowe RJ, Vogeli A, Alan M, Christ-Crain M, Thomann R, et al. Long-term Prognosis in COPD Exacerbation: Role of Biomarkers, Clinical Variables and Exacerbation Type. COPD. 2015;12(3):295305.

27. Tanriverdi H, Ornek T, Erboy F, Altinsoy B, Uygur F, Atalay F, Tor MM. Comparison of diagnostic values of procalcitonin, C-reactive protein and blood neutrophil/ lymphocyte ratio levels in predicting bacterial infection in hospitalized patients with acute exacerbations of COPD. Wien Klin Wochenschr. 2015;127(19-20):756-763.

28. Chang CH, Tsao KC, Hu HC, Huang CC, Kao KC, Chen $\mathrm{NH}$, Yang $\mathrm{CT}$, et al. Procalcitonin and C-reactive protein cannot differentiate bacterial or viral infection in COPD exacerbation requiring emergency department visits. Int J Chron Obstruct Pulmon Dis. 2015;10:767-774.

29. Ergan B, Sahin AA, Topeli A. Serum Procalcitonin as a Biomarker for the Prediction of Bacterial Exacerbation and Mortality in Severe COPD Exacerbations Requiring Mechanical Ventilation. Respiration. 2016;91(4):316324.

30. Wang JX, Zhang SM, Li XH, Zhang Y, Xu ZY, Cao B. Acute exacerbations of chronic obstructive pulmonary disease with low serum procalcitonin values do not benefit from antibiotic treatment: a prospective randomized controlled trial. Int J Infect Dis. 2016;48:40-45.

31. Corti C, Fally M, Fabricius-Bjerre A, Mortensen K, Jensen BN, Andreassen HF, Porsbjerg C, et al. Point-ofcare procalcitonin test to reduce antibiotic exposure in patients hospitalized with acute exacerbation of COPD. Int J Chron Obstruct Pulmon Dis. 2016;11:1381-1389.

32. Picart J, Moiton MP, Gauzere BA, Gazaille V, Combes X, DiBernardo S. Introduction of a PCT-based algorithm to guide antibiotic prescription in COPD exacerbation. Med Mal Infect. 2016;46(8):429-435.

33. Zhu JJ, Liu LJ. Analysis of factors influenced by the effectiveness of non-invasive ventilation in the treatment of acute exacerbation of chronic obstructive pulmonary disease with different severities. Eur Rev Med Pharmacol Sci. 2016;20(22):4775-4781.

34. Pizzini A, Lunger F, Sahanic A, Nemati N, Fuchs D, Weiss G, Kurz K, et al. Diagnostic and prognostic value of inflammatory parameters including neopterin in the setting of pneumonia, COPD, and acute exacerbations. COPD. 2017;14(3):298-303.

35. Flattet Y, Garin N, Serratrice J, Perrier A, Stirnemann J, Carballo S. Determining prognosis in acute exacerbation of COPD. Int J Chron Obstruct Pulmon Dis. 2017;12:467475.

36. Kawamatawong T, Apiwattanaporn A, Siricharoonwong W. Serum inflammatory biomarkers and clinical outcomes of COPD exacerbation caused by different patho- 
gens. Int J Chron Obstruct Pulmon Dis. 2017;12:16251630.

37. Gao D, Chen X, Wu H, Wei H, Wu J. The levels of serum pro-calcitonin and high-sensitivity C-reactive protein in the early diagnosis of chronic obstructive pulmonary disease during acute exacerbation. Exp Ther Med. 2017;14(1):193-198.

38. Colak A, Yilmaz C, Toprak B, Aktogu S. Procalcitonin and CRP as biomarkers in discrimination of Communityacquired Pneumonia and Exacerbation of COPD. J Med Biochem. 2017;36(2):122-126.

39. Li Y, Xie L, Xin S, Li K. Values of procalcitonin and Creactive proteins in the diagnosis and treatment of chronic obstructive pulmonary disease having concomitant bacterial infection. Pak J Med Sci. 2017;33(3):566-569.

40. Bremmer DN, DiSilvio BE, Hammer C, Beg M, Vishwanathan S, Speredelozzi D, Moffa MA, et al. Impact of procalcitonin guidance on management of adults hospitalized with chronic obstructive pulmonary disease exacerbations. J Gen Intern Med. 2018;33(5):692-697.

41. Chang C, Yao WZ, Chen YH, Liu ZY, Zhang XW. [Value of serum procalcitonin in diagnosing bacterial lower respiratory tract infections in people with exacerbation of Chronic Obstructive Pulmonary Disease]. Beijing Da
Xue Xue Bao Yi Xue Ban. 2006;38(4):389-392.

42. Daubin C, Parienti JJ, Fradin S, Vabret A, Ramakers M, Terzi N, Freymuth F, et al. Procalcitonin levels and bacterial aetiology among COPD patients admitted to the ICU with severe pneumonia: a prospective cohort study. BMC Infect Dis. 2009;9:157.

43. Lin C, Pang Q. Meta-analysis and systematic review of procalcitonin-guided treatment in acute exacerbation of chronic obstructive pulmonary disease. Clin Respir J. 2018;12(1):10-15.

44. Mathioudakis AG, Chatzimavridou-Grigoriadou V, Corlateanu A, Vestbo J. Procalcitonin to guide antibiotic administration in COPD exacerbations: a meta-analysis. Eur Respir Rev. 2017;26(143).

45. van der Maas ME, Mantjes G, Steuten LM. Procalcitonin biomarker algorithm reduces antibiotic prescriptions, duration of therapy, and costs in chronic obstructive pulmonary disease: a comparison in the Netherlands, Germany, and the United Kingdom. OMICS. 2017;21(4):232-243.

46. Lindenauer PK, Shieh MS, Stefan MS, Fisher KA, Haessler SD, Pekow PS, Rothberg MB, et al. Hospital procalcitonin testing and antibiotic treatment of patients admitted for chronic obstructive pulmonary disease exacerbation. Ann Am Thorac Soc. 2017;14(12):1779-1785. 